\title{
Radical versus supraomohyoid neck dissection in the treatment of squamous cell carcinoma of the inferior level of the mouth
}

\author{
Abrão Rapoport ${ }^{1}$, Daniel Kanabben Ortellado ${ }^{2}$, Ali \\ Amar 3 , Carlos Neutzling Lebn ${ }^{4}$, Rogério Aparecido \\ Dedivitis5, Ricardo Salinas Perez, Helen Mara \\ Rodrigues $^{7}$
}

Keywords: mouth, key words: neck dissection, radical, supraomohyoid.

\section{Summary}

T he therapeutic paradigm for neck metastasis of squamous cell carcinoma (SCC) in the lower level of the mouth has changed due to survival. Aim: A comparative study between radical (RND) versus selective neck dissection (SND). Material and Method: An analysis of mouth SCC in the lower level of the mouth in 460 files from the Head \& Neck and ORL Department of the Heliopolis Hospital, from 1978 to 2002. In the RND the metastathic rate in levels IV and V was assessed; in the SND the presence and site of recurrence was identified. The chi square test with the Yates correction was the chosen statistical method. Results: In the RND the metastatic rates were 5.8\% (level IV) and 4.6\% (level V) for cNO cases, and 9.9\% (level IV) and 5.9\%(level V) for $\mathrm{cN}+$ cases; for level I only the rates were $11,0 \%$ for cNO cases and $5.5 \%$ for $\mathrm{cN}+$ cases. In the SND the number of recurrences was $4(4.1 \%)$ in 97 neck dissections (pNO) and 2 (10\%) in 20 neck dissections ( $\mathrm{pN}+$ ). There was no advantage in using radiation compared to non-irradiated cases (5.6\% and 5.7\%). Conclusion: The SND may be used for SCC of the lower level of the mouth.

${ }^{1}$ Professor in the USP Medical School. Technical Director of the Health Dept. - Heliopolis Hospital.

${ }^{2}$ Master in health sciences, HOSPHEL, Heliopolis Hospital, Sao Paulo.

${ }^{3}$ Doctor, Otorhinolaryngology Department, UNIFESP - Sao Paulo Federal University, Physician and surgeon of the Otorhinolaryngology and Head \& Neck Department, HOSPHEL - Heliopolis Hospital, Sao Paulo.

${ }^{4}$ Doctor, Otorhinolaryngology Department, UNIFESP - Sao Paulo Federal University. Head of the Otorhinolaryngology and Head \& Neck Surgery, HOSPHEL - Heliopolis Hospital, Sao Paulo.

${ }^{5}$ Doctor, Otorhinolaryngology Department, UNIFESP - Sao Paulo Federal University, Permanent faculty of the graduation course in medicine (Health Sciences), HOSPHEL, Heliopolis Hospital, Sao Paulo.

'Master's degree student - Medicine (Health Sciences), HOSPHEL - Heliopolis Hospital, Sao Paulo.

7 Master's degree student - Medicine (Health Sciences), HOSPHEL - Heliopolis Hospital, Sao Paulo.

Research work conducted in the Otorhinolaryngology and Head \& Neck Surgery Department, Heliopolis Hospital, Hosphel/SP, Brazil.

Address for correspondence: Prof. Dr. Abrão Rapoport - Rua Iramaia 136 Jd. Europa 01450-020 São Paulo SP.

Paper submitted to the ABORL-CCF SGP (Management Publications System) on July 18th, 2006 and accepted for publication on Augusty 26 th, 2006. cod. 3219. 


\section{INTRODUCTION}

The presence of lymphatic cervical metastases in patients bearing epidermoid carcinoma (or squamous cell carcinoma) of the lower portion of the mouth predicts an unfavorable prognosis. This explains a constant concern and strategy changes in the treatment of the neck with this malignancy. Originally, radical neck dissection was the rule for therapy. ${ }^{1}$ This approach started to be questioned due to lack of disease control ${ }^{2}$ and increased knowledge about visceral compartments that justified the preservation of non-lymphatic structures of the neck (jugular vein, spinal nerve and the sternocleidomastoid muscle).,34 After the 1970s, new studies revealed that lymphatic metastasizing into various neck regions followed a selective pattern according to the site of the primary tumor ${ }^{5-7}$ This made it possible to progressively systematize selective neck dissection, where results were similar those obtained from radical neck dissection, although some of the lymphatic chains were not resected. 8 These findings enabled physicians to recommend selective neck dissection with oncological safety. Initially, this procedure was used in necks with no metastatic lymph nodes (cNO) and in those cases with lymph node metastases up to $2 \mathrm{~cm}$ with no rupture of the capsule (pN1).9-17 These studies underlined our proposition to change the extension of neck dissection for the surgical treatment of necks with clinical metastases (cN1) from squamous cell carcinoma in the lower region of the mouth. We based our proposition on the follow-up of patients and the diagnosis of lymph node recurrence in those anatomical regions not included in the selective procedure.

\section{MATERIAL AND METHOD}

A retrospective analysis was made of 460 charts of patients diagnosed with squamous cell carcinoma in the lower region of the mouth. The Research Ethics Committee approved the trial (number 353). Eligibility criteria were as follows: previously untreated patients with squamous cell carcinoma in the lower region of the mouth (tongue, floor of the mouth, retromolar region and the lower gingiva) that underwent radical or selective (supraomohyoid) neck dissection, with a minimum follow-up period of 12 months or until death.18 Patients were classified according to age, sex, site of the primary tumor, and clinical and pathological staging (TNM 2002). The mean age was 54.5 years, the median age was 53 years $(\mathrm{Q} 25-75 \%=47-62)$, the minimum age was 22 years and the maximum age was $87 y$ years. There were 406 men (88.3\%) and 54 women (11.7\%), an 8:1 ratio. The tumor sites were the floor of the mouth (180 cases, 39.1\%), the tongue (136 cases, 29.6\%), the retromolar region (74 cases, 16.1\%) and the lower gingiva (70 cases, $15.2 \%$ ).

Staging of the primary tumor was as follows: 14 cases were T1 (3.0\%), 157 cases were T2 (34.1\%), 146 cases were $\mathrm{T} 3$ (31.8\%), 138 cases were $\mathrm{T} 4$ (30.0\%) and five cases were $5 \mathrm{Tx}(1.1 \%)$. Clinical staging of the neck was as follows: 227 cases were cN0 (49.3\%) and 233 cases were $\mathrm{cN}+(50.7 \%)$, of which 119 cases were N1 (25.9\%), 18 cases were N2a (3.9\%), 58 cases were N2b (12.6\%), 23 cases were N2c (5.0\%), 14 cases were N3 (3.0\%) and 1 case was Nx (0.2\%) (Table 1). Patients were grouped according to the clinical stage of the disease, as follows: Stage I - 8 cases (1.7\%), Stage II - 101 cases (21.9\%), Stage III - 152 cases (33.1\%) and Stage IV - 196 cases (42.6\%). Clinical staging was impossible in three cases $(0.7 \%)$.

The pN staging was as follows: 214 cases (46.5\%) were pNO and 246 cases $(53.5 \%)$ were $\mathrm{pN}+$, of which 62 cases (13.5\%) were pN1, 7 cases (1.5\%) were N2a, 138 cases $(30.0 \%)$ were pN2b, 23 cases $(5.0 \%)$ were pN2c, 5 cases (1.1\%) were pN3 and 11cases (2.4\%) were unclassifiable (pNx) (Table 2).

All of the patients underwent elective/therapeutic treatment of the primary tumor and the neck simultaneously. Surgery was unilateral or bilateral radical or selective (supraomohyoid) neck dissection. Local, regional and distance recurrences were assessed, as were second primary tumors and their sites. In regional recurrences, control rates of the primary tumor, the site of recurrence (within or out of the operated area) and the rate of postoperative radiotherapy were evaluated.

Statistics comprised the descriptive method; qualitative variables were evaluated using the chi-square test with the Yates correction. The Statistica 5.0 (Statsoft, USA) software was used.

\section{RESULTS}

There were 445 radical neck dissections, distributed according to metastasizing levels (Table 3). In 273 cases $\mathrm{N}+$ that excluded $2 \mathrm{Nx}$, the cases were distributed according to those levels and TNM staging (Table 4). The distribution of lymph nodes according to the four sites of the lower region of the mouth was sub-classified for the 387 radical neck dissections (Table 5). In supraomohyoid neck dissections (among the total 573), 22 cases (17.1\%) presented metastatic lymph node involvement ( $\mathrm{pN}+$ ); 106 cases (82.9\%) had no metastases on histopathology (pN0). The rates of local, regional and local-regional recurrence are shown on Table 6 for those 106 pN0 cases (82.9\%). There was regional recurrence in 27 cases (6.1\%) of 445 neck dissections. Of these 7 cases (4.0\%) were pN0 and 20 cases (7.3\%) were $\mathrm{pN}+$. In those $7 \mathrm{pNO}$ cases, 5 cases recurred within the dissection area and 2 recurred in the contralateral side of the neck; these 7 were not irradiated. Of the $20 \mathrm{pN}+\mathrm{ca}-$ ses, $11(2,2 \%)$ occurred in the neck, 2 within the dissected area and 9 in the contralateral side of the neck; 4 of these cases were irradiated. Regional recurrence occurred in 9 cases (7.1\%) of 128 supraomohyoid neck dissections, of 
Table 1. Clinical $\mathrm{T}$ and $\mathrm{N}$ staging (cT and $\mathrm{cN}$ ) of 460 patients with squamous cell carcinoma of the oral cavity.

\begin{tabular}{ccccccccc}
\hline & cN0 & cN1 & cN2a & cN2b & cN2c & cN3 & cNx & TOTAL\% \\
\hline cT1 & 8 & 1 & 0 & 2 & 1 & 1 & 1 & $14(3,0 \%)$ \\
cT2 & 101 & 38 & 2 & 11 & 1 & 4 & 0 & $157(34,1 \%)$ \\
cT3 & 71 & 41 & 6 & 20 & 5 & 16 & 0 & $146(31,8 \%)$ \\
cT4 & 45 & 37 & 9 & 25 & 0 & 0 & $138(30,0 \%)$ \\
CTx & 2 & 2 & 1 & 18 & 58 & 23 & 14 & 1 \\
\hline \multirow{2}{*}{ TOTAL } & 227 & 119 & $(3,9 \%)$ & $(12,6 \%)$ & $(5,0 \%)$ & $(3,0 \%)$ & $(0,2 \%)$ & $(100,0 \%)$ \\
\hline
\end{tabular}

$\mathrm{T}$ = staging of the primary tumor - TNM. N = staging of lymph node metastasis - TNM

Table 2. Comparative study of $\mathrm{cN}$ and $\mathrm{pN}$ parameters.

\begin{tabular}{|c|c|c|c|c|c|c|c|c|}
\hline \multirow{2}{*}{$\begin{array}{c}\text { Clinical N } \\
\text { stage }\end{array}$} & \multicolumn{7}{|c|}{ Stage N, on pathology } & \multirow{2}{*}{ TOTAI } \\
\hline & $\mathrm{pNO}$ & $\mathrm{pN} 1$ & $\mathrm{pN} 2 \mathrm{a}$ & $\mathrm{pN} 2 \mathrm{~b}$ & $\mathrm{pN} 2 \mathrm{c}$ & $\mathrm{pN} 3$ & $\mathrm{pNx}$ & \\
\hline NO & $\begin{array}{c}152 \\
(66,9 \%)\end{array}$ & $\begin{array}{c}29 \\
(12,8 \%)\end{array}$ & 0 & $\begin{array}{c}41 \\
(18,1 \%)\end{array}$ & $\begin{array}{c}1 \\
(0,4 \%)\end{array}$ & 0 & $\begin{array}{c}4 \\
(1,8 \%)\end{array}$ & $\begin{array}{c}227 \\
(100 \%)\end{array}$ \\
\hline N1 & $41(34,5 \%)$ & $\begin{array}{c}19 \\
(15,9 \%)\end{array}$ & $\begin{array}{c}2 \\
(1,7 \%)\end{array}$ & $\begin{array}{c}48 \\
(40,3 \%)\end{array}$ & $\begin{array}{c}4 \\
(3,4 \%)\end{array}$ & 0 & $\begin{array}{c}5 \\
(4,2 \%)\end{array}$ & $\begin{array}{c}119 \\
(100 \%)\end{array}$ \\
\hline $\mathrm{N} 2 \mathrm{a}$ & $\begin{array}{c}2 \\
(11,1 \%)\end{array}$ & $\begin{array}{c}4 \\
(22,2 \%)\end{array}$ & $\begin{array}{c}2 \\
(11,1 \%)\end{array}$ & $\begin{array}{c}7 \\
(38,9 \%)\end{array}$ & $\begin{array}{c}3 \\
(16,7 \%)\end{array}$ & 0 & 0 & $\begin{array}{c}18 \\
(100 \%)\end{array}$ \\
\hline $\mathrm{N} 2 \mathrm{~b}$ & $\begin{array}{c}11 \\
(18,9 \%)\end{array}$ & $\begin{array}{c}8 \\
(13,8 \%)\end{array}$ & $\begin{array}{c}2 \\
(3,5 \%)\end{array}$ & $\begin{array}{c}30 \\
(51,7 \%)\end{array}$ & $\begin{array}{c}5 \\
(8,6 \%)\end{array}$ & 0 & $\begin{array}{c}2 \\
(3,5 \%)\end{array}$ & $\begin{array}{c}58 \\
(100 \%)\end{array}$ \\
\hline $\mathrm{N} 2 \mathrm{c}$ & $\begin{array}{c}6 \\
(26,1 \%)\end{array}$ & $\begin{array}{c}2 \\
(8,7 \%)\end{array}$ & 0 & $\begin{array}{c}5 \\
(21,7 \%)\end{array}$ & $\begin{array}{c}10 \\
(43,5 \%)\end{array}$ & 0 & 0 & $\begin{array}{c}23 \\
(100 \%)\end{array}$ \\
\hline N3 & $\begin{array}{c}2 \\
(14,3 \%)\end{array}$ & 0 & $\begin{array}{c}1 \\
(7,1 \%)\end{array}$ & $\begin{array}{c}6 \\
(42,9 \%)\end{array}$ & 0 & $\begin{array}{c}5 \\
(35,7 \%)\end{array}$ & 0 & $\begin{array}{c}14 \\
(100 \%)\end{array}$ \\
\hline TOTAL & 214 & 62 & 7 & 138 & 23 & 5 & 11 & 460 \\
\hline
\end{tabular}

$\mathrm{N}=$ clinical staging of lymph node metastasis - TNM, pN = staging of lymph node metastasis on pathology - TNM

Table 3. Distribution of cervical metastases in 445 radical neck dissections - 172 clinically NO (cNO) and 273 clinically positive (cN+).

\begin{tabular}{ccc}
\hline Neck levels & cNO & cN+ \\
\hline la & $3(1,7 \%)$ & $18(6,6 \%)$ \\
Ib & $11(6,4 \%)$ & $64(23,4 \%)$ \\
Ila & $35(20,3 \%)$ & $122(44,7 \%)$ \\
Ilb & $7(4,1 \%)$ & $15(5,5 \%)$ \\
III & $18(10,5 \%)$ & $57(20,9 \%)$ \\
IV & $10(5,8 \%)$ & $27(9,9 \%)$ \\
V & $8(4,6 \%)$ & $16(5,9 \%)$ \\
\hline TOTAL & 172 & 273 \\
\hline
\end{tabular}

$\mathrm{cNO}=$ no clinically palpable metastases, $\mathrm{cN}+=$ clinically palpable metastases 
Table 4. Distribution of lymph node involvement in different levels of the neck according to clinical staging.

\begin{tabular}{|c|c|c|c|c|c|}
\hline \multirow{2}{*}{ Levels } & \multicolumn{5}{|c|}{ Staging (number of neck dissections) } \\
\hline & cN1 - 122 & $\mathrm{cN} 2 \mathrm{a}-22$ & $\mathrm{cN} 2 \mathrm{~b}-67$ & $\mathrm{cN} 2 \mathrm{c}-41$ & cN3 - 19 \\
\hline la & $4(3,3 \%)$ & $1(4,5 \%)$ & $6(8,9 \%)$ & $6(14,6 \%)$ & $1(5,3 \%)$ \\
\hline Ila & $51(41,8 \%)$ & $15(68,2 \%)$ & $33(49,2 \%)$ & $15(36,6 \%)$ & $7(36,8 \%)$ \\
\hline $\mathrm{Ilb}$ & $5(4,1 \%)$ & 0 & $7(10,4 \%)$ & 0 & $3(15,8 \%)$ \\
\hline IV & $12(9,8 \%)$ & $1(4,5 \%)$ & $5(7,5 \%)$ & $6(14,6 \%)$ & $3(15,8 \%)$ \\
\hline $\mathrm{V}$ & $4(3,3 \%)$ & $2(9,1 \%)$ & $6(8,9 \%)$ & $2(4,9 \%)$ & $2(10,5 \%)$ \\
\hline
\end{tabular}

$\mathrm{cN}=$ clinical staging of lymph node metastases - TNM

Table 5. Distribution of lymph node involvement in neck levels and sub-levels in 387 patients undergoing radical neck dissection for tongue, gingiva, floor of the mouth and retromolar tumors, in $\mathrm{cNO}$ and $\mathrm{cN}+$ cases.

\begin{tabular}{|c|c|c|c|c|c|c|c|}
\hline & la & $\mathrm{Ib}$ & Ila & llb & III & IV & V \\
\hline RETR NO & 0 & 2 & 11 & 1 & 2 & 3 & 1 \\
\hline RETR N+ & 2 & 8 & 17 & 2 & 3 & 0 & 1 \\
\hline SOAL NO & 1 & 4 & 9 & 1 & 5 & 1 & 4 \\
\hline SOAL N+ & 7 & 26 & 38 & 5 & 28 & 12 & 7 \\
\hline GENG NO & 2 & 4 & 6 & 2 & 2 & 3 & 0 \\
\hline GENG N+ & 5 & 14 & 14 & 0 & 3 & 3 & 1 \\
\hline LÍNG NO & 0 & 1 & 9 & 3 & 9 & 3 & 3 \\
\hline LÍNG N+ & 4 & 10 & 44 & 8 & 20 & 11 & 7 \\
\hline
\end{tabular}

$\mathrm{N} 0=$ no clinically palpable metastases, $\mathrm{N}+=$ clinically palpable metastases

RETR $=$ retromolar region, SOAL = floor of the mouth, GENG = gingiva, LING = tongue

Table 6. Local recurrence $(R L)$, regional recurrence $(R R)$ and localregional recurrence $(\mathrm{RL}+\mathrm{RR})$ in $\mathrm{pNO}$ patients undergoing supraomohyoid neck dissection.

\begin{tabular}{cccc}
\hline Neck dissection(n) & RL & RR & RL + RR \\
\hline ESOH (48) & $12(25,0 \%)$ & $4(8,3 \%)$ & $5(10,4 \%)$ \\
EC + ESOH (13) & $2(15,4 \%)$ & $1(7,7 \%)$ & $2(15,4 \%)$ \\
ESOHB (10) & $2(20,0 \%)$ & $1(10,0 \%)$ & 0 \\
\hline
\end{tabular}

$\mathrm{ESOH}=$ unilateral supraomohyoid neck dissection; $\mathrm{EC}+\mathrm{ESOH}=$ radical neck dissection + supraomohyoid neck dissection; $\mathrm{ESOHB}=$ bilateral supraomohyoid neck dissection.
Table 7. Local recurrence (RL). regional recurrence (RR) and localregional recurrence $(R L+R R)$ in $\mathrm{pN}+$ patients undergoing supraomohyoid neck dissection

\begin{tabular}{cccc}
\hline Neck dissection(n) & $\mathrm{RL}$ & $\mathrm{RR}$ & $\mathrm{RL}+\mathrm{RR}$ \\
\hline $\mathrm{ESOH}(9)$ & $2(22,2 \%)$ & $1(11,1 \%)$ & $1(11,1 \%)$ \\
EC + ESOH (25) & $6(24,0 \%)$ & $4(16,0 \%)$ & $1(4,0 \%)$ \\
ESOHB (6) & $2(33,3 \%)$ & 0 & 0 \\
\hline
\end{tabular}

$\mathrm{ESOH}=$ unilateral supraomohyoid neck dissection; $\mathrm{EC}+\mathrm{ESOH}=$ radical neck dissection + supraomohyoid neck dissection; ESOHB = bilateral supraomohyoid neck dissection. 
Table 8. Recurrence according to the type of neck dissection and the absence ( $\mathrm{pN} 0)$ and presence $(\mathrm{pN}+)$ of metastases on histology

\begin{tabular}{ccccc}
\hline $\begin{array}{c}\text { Neck dissection/ } \\
\text { Isolated regional recur- } \\
\text { rence }\end{array}$ & Radical & Supraomohyoid & Total & p \\
\hline pN0 & $5(157)=3,1 \%$ & $4(97)=4,1 \%$ & $9 / 254=3,5 \%$ & 0,96 \\
pN+ & $11(253)=4,3 \%$ & $2(20)=10,0 \%$ & $13 / 273=4,7 \%$ & 0,24 \\
\hline Total & $16(40)=3,9 \%$ & $6(117)=5,1 \%$ & $6 / 117=5,1 \%$ & - \\
\hline
\end{tabular}

which 6 cases (7.3\%) were pN0 and 3 cases were pN+ (6.5\%). Recurrence was within the dissected area in 2 of the $6 \mathrm{pN} 0$ cases, and in the contralateral side of the neck in 2 cases; none of these cases were irradiated. In $3 \mathrm{pN}+$ recurrence cases one occurred within the dissected area, another case was ipsilateral, not in the dissected area (no adjuvant radiotherapy was used in these two cases), and a third case recurred in the contralateral side of the neck (this patient underwent postoperative radiotherapy). In 22 $\mathrm{pN}+$ patients there were level Ia metastases in 5 cases, Ib metastases in 6 cases, IIa metastases in 8 cases and level III metastases in 7 cases. Table 7 shows local (RL), regional (RR) and local-regional (RL+RR) recurrences in this group. There was no statistically significant difference between the absence ( $\mathrm{pNO}$ ) and presence ( $\mathrm{pN}+$ ) of metastases on histology and the diagnosis of isolated regional recurrence (Table 8) as a function of neck dissection. Finally, there was no significance in the incidence of isolated unilateral events in 230 unilateral neck dissections $(p=1.0)$. Radiotherapy was done in 9 cases $(5.6 \%)$ of recurrence out of 160 neck dissections; 4 cases of recurrence (5.7\%) out of 70 were not irradiated.

\section{DISCUSSION}

One of the methods of assessing the feasibility of therapeutic selective (supraomohyoid) neck dissection is to study the distribution of $\mathrm{cNO}$ and $\mathrm{cN}+$ levels in the 445 radical neck dissections (Table 3). Level IV was seen in 9.9\% of cases and level V was seen in 5.9\% of cases; Shah found a 3\% rate of level IV involvement for NO cases and $15 \%$ for $\mathrm{N}+$ cases. This author also noted that level $\mathrm{V}$ was rarely involved and was always accompanied by metastases in other lymph node levels. Based on this analysis three forms or recurrence were defined in or out of the dissected area and unilateral or contralateral. Our results were $3.9 \%$ in radical neck dissection and $5.1 \%$ in supraomohyoid neck dissection; these results are similar to those reported in the literature ${ }^{9,12}$ in which the respective values are $9.3 \%$ and $10.2 \%$. Our analysis of recurrence and the presence of metastases verified on histology, we found $3.5 \%$ for $\mathrm{pN} 0$, and $4.7 \%$ for $\mathrm{pN}+$, while these numbers in the literature are $5 \%$ and $10 \% .{ }^{19}$

In cases of recurrence, 5,6\% of cases underwent radiotherapy and $5,7 \%$ of cases had no radiotherapy, which is similar to the literature. .,14,20-22 $^{2}$
We concluded that the choice of supraomohyoid neck dissection for squamous cell carcinoma in the lower region of the mouth is feasible without compromising oncological results.

\section{CONCLUSION}

The choice of selective neck dissection in levels I to IV in cases of squamous cell carcinoma in the lower region of the mouth associated with palpable metastases at level I is feasible without loss of oncological results.

\section{REFERENCES}

1. Crile G. Excision of cancer of the head and neck. JAMA 1906;47:17806.

2. Strong E. Preoperative radiation and radical neck dissection. Surg Clin North Am 1969;49:271-6.

3. Suarez O. El problema de las metastasis linfaticas y alejadas del cancer de laringe e hipofaringe. Rev Otorhinolaringol Santiago 1963;23:8399.

4. Bocca E, Pignataro O, Oldini C, Cappa C. Functional neck dissection an evaluation and review of 843 cases. Laryngoscope 1984;94:9425 .

5. Carvalho M, Sobrinho J, Rapoport A, Fava AS, Kanda JL, Lehn CN Chacra J, Walder F, Menezes M, Negri SLC. Padrão e comportamento das metástases cervicais do carcinoma de laringe e de hipofaringe. Rev Bras Otorrinolaringol 1996;62:122-9.

6. Lindberg R. Distribution of cervical lymph node metastases from squamous cell carcinoma of the upper respiratory and digestive tracts. Cancer 1972;29:1446-9.

7. Woolgar J. Histological distribution of cervical lymph node metastases from intraoral / oropharyngeal squamous cell carcinoma. Br J Oral Maxillofac Surg 1999;37:175-80.

8. Robbins K, Clayman G, Levine P, Medina J, Sessions R, Shaha A, Som P, Wolf GT. Neck dissection classification update - Revisions proposed by the American Head and Neck Society and the American Academy of Otolaryngology - Head And Neck Surgery. Arch Otolaryngol Head Neck Surg 2002;128:751-8.

9. Spiro R, Spiro J, Strong E. Surgical approach to squamous carcinoma confined to the tongue and the floor of the mouth. Head Neck Surg 1986;9:27-31.

10. Clayman G, Frank D. Selective neck dissection of anatomically levels is as efficacious as modified radical neck dissection for elective treatment of the clinically negative neck in patients with squamous cell carcinoma of the upper respiratory and digestive tracts. Arch Otolaryngol Head Neck Surg 1998;124:348-53.

11. Brazilian Head and Neck Cancer Study Group. Results of a prospective trial on elective modified radical classical versus supraomohyoid neck dissection in the management of oral squamous carcinoma. Am J Surg 1998;176:422-7.

12. Byers R, Clayman G, McGill D, Andrews T, Kare R, Roberts D, Goepfert H. Selective neck dissections for squamous carcinoma of the upper aerodigestive tract: Patterns of regional failure. Head Neck 1999;21:499-505. 
13. Ambrosch P, Kron M, Pradier O, Steiner W. Efficacy of selective neck dissection: A review of 503 cases of elective and therapeutic treatment of the neck in squamous cell carcinoma of the upper aerodigestive tract. Otolaryngol Head Neck Surg 2001;124:180-7.

14. Kowalski L, Carvalho A. Feasibility of supraomohyoid neck dissection in N1 and N2a oral cancer patients. Head Neck 2002;24:921-4.

15. Amar A, Franzi S, Rapoport A. Evolution of patients with squamous cell carcinoma of upper aerodigestive tract. Sao Paulo Med J 2003;121:155-8.

16. Ferlito A, Rinaldo A, Robbins K, Leemans C, Shah J, Andersen P, Kowalski L, Pellitteri P, Clayman G, Rogers S, Medina J, Byers R. Changing concepts in the surgical management of the cervical node metastasis. Oral Oncology 2003;39:429-35.

17. Elsheikh M, Mahfouz M, Elsheikh E. Level IIb lymph nodes metastasis in elective supraomohyoid neck dissection for oral cavity squamous cell carcinoma: A molecular-based study. Laryngoscope 2005;115:1636-40.
18. Chepeha D, Hoff P, Taylor R, Bradford C, Teknos T, Esclamado R. Selective neck dissection for the treatment of neck metastasis from squamous cell carcinoma of the head and neck. Laryngoscope 2002;112:434-8.

19. Medina J, Byers R. Supraomohyoid neck dissection: Rationale, indications and surgical technique. Head Neck 1989;11:111-22.

20. Kolli V, Datta R, Orner J, Hicks W, Loree T. The role of supraomohyoid neck dissection in patients with positive nodes. Arch Otolaryngo Head Neck Surg 2000;126:413-6.

21. Muzaffar K. Therapeutic selective neck dissection: A 25-year review. Laryngoscope 2003;113:1460-5.

22. Shah J, Candela F, Poddar A. The patterns of cervical lymph node metastases from squamous carcinoma of the oral cavity. Cancer 1990;66:109-13. 